Research paper

\title{
Ordered mesoporous silica to enhance the bioavailability of poorly water-soluble drugs: Proof of concept in man
}

\author{
Katarina Bukara ${ }^{\mathrm{a}, \mathrm{b}, *}$, Laurent Schueller ${ }^{\mathrm{c}}$, Jan Rosier ${ }^{\mathrm{c}}$, Mark A. Martens ${ }^{\mathrm{c}}$, Tinne Daems ${ }^{\mathrm{c}}$, Loes Verheyden ${ }^{\mathrm{c}}$, \\ Siemon Eelen ${ }^{c}$, Michiel Van Speybroeck ${ }^{\mathrm{c}}$, Cristian Libanati ${ }^{\mathrm{d}}$, Johan A. Martens ${ }^{\mathrm{e}}$, Guy Van Den Mooter ${ }^{\mathrm{f}}$, \\ Françoise Frérart $^{\mathrm{g}}$, Koen Jolling ${ }^{\mathrm{h}}$, Marjan De Gieter ${ }^{\mathrm{h}}$, Branko Bugarski ${ }^{\mathrm{b}}$, Filip Kiekens ${ }^{\text {a }}$
}

${ }^{a}$ Laboratory for Pharmaceutical Technology and Biopharmacy, University of Antwerp, Universiteitsplein 1, B-2610 Wilrijk, Belgium

${ }^{\mathrm{b}}$ Department of Chemical Engineering, Faculty of Technology and Metallurgy, University of Belgrade, Belgrade, Serbia

${ }^{\mathrm{c}}$ Formac Pharmaceuticals NV, Gaston Geenslaan 1, B-3001 Heverlee, Belgium

${ }^{\mathrm{d}}$ W.R. Grace \& Co., Incubator Technologies, 7500 Grace Drive, Columbia, MD 21044, United States

e Center for Surface Chemistry and Catalysis, KU Leuven, Kasteelpark Arenberg 23, B-3001 Heverlee, Belgium

${ }^{\mathrm{f}}$ Laboratory of Pharmacotechnology and Biopharmacy, KU Leuven, O\&N2, Herestraat 49, Box 921, B-3000 Leuven, Belgium

${ }^{8}$ SGS Lab Simon SA, Vieux Chemin du Poète 10, B-1301 Bierges-Wavre, Belgium

${ }^{\mathrm{h}}$ SGS Belgium NV, Intercity Business Park, Generaal De Wittelaan 19, B-2800 Mechelen, Belgium

\section{A R T I C L E I N F O}

\section{Article history:}

Received 30 June 2016

Accepted in revised form 23 August 2016

Available online 17 September 2016

\section{Keywords:}

Ordered mesoporous silica

Solubility

Absorption

Bioavailability

Fenofibrate

\begin{abstract}
A B S T R A C T
Formulating poorly water soluble drugs using ordered mesoporous silica materials is an emerging approach to tackle solubility-related bioavailability problems. The current study was conducted to assess the bioavailability-enhancing potential of ordered mesoporous silica in man. In this open-label, randomized, two-way cross-over study, 12 overnight fasted healthy volunteers received a single dose of fenofibrate formulated with ordered mesoporous silica or a marketed product based on micronized fenofibrate. Plasma concentrations of fenofibric acid, the pharmacologically active metabolite of fenofibrate, were monitored up to $96 \mathrm{~h}$ post-dose. The rate $\left(C_{\max } /\right.$ dose increased by $77 \% ; t_{\max }$ reduced by $\left.0.75 \mathrm{~h}\right)$ and extent of absorption ( $\mathrm{AUC}_{0-24 \mathrm{~h}} /$ dose increased by $54 \%$ ) of fenofibrate were significantly enhanced following administration of the ordered mesoporous silica based formulation. The results of this study serve as a proof of concept in man for this novel formulation approach.
\end{abstract}

(c) 2016 Elsevier B.V. All rights reserved.

\section{Introduction}

Ordered mesoporous silica (OMS) materials have recently emerged as carriers for the oral delivery of poorly water-soluble drugs. These materials are mesoporous, meaning that the pore diameter is between 2 and $50 \mathrm{~nm}$ (IUPAC definition), and ordered in crystallographic sense meaning that the mesopores are uniform in size and organized in a regular manner in the silica matrix which itself is amorphous.

Deposition of an active pharmaceutical ingredient (API) in the mesopores of the carrier, typically conducted via solvent-based impregnation techniques, is associated with a suppression of recrystallization of the entrapped molecules by virtue of finitesize effects [1] and as such mesoporous silica materials are excellent stabilizers for amorphous APIs [2-4]. When a mesoporous sil-

\footnotetext{
* Corresponding author at: Department of Chemical Engineering, Faculty of Technology and Metallurgy, University of Belgrade, Belgrade, Serbia.

E-mail address: katarinabukara@gmail.com (K. Bukara).
}

ica material loaded with a poorly water-soluble API is exposed to aqueous media, the release rate of the API from the silica material is typically faster than the dissolution rate of crystalline form [2] and often associated with the generation of a supersaturated API solution [5-7] which offers the potential to increase bioavailability as demonstrated in non-clinical models for drugs such as itraconazole [8,9], glibenclamide [6] and ezetimibe [3].

Some of us have developed an OMS material which is very convenient in terms of its synthesis [10] and suitable for the delivery of poorly water-soluble drugs [3]. A very recent paper from our group reported on the use of this OMS material for the bioavailability enhancement of the poorly soluble API fenofibrate in beagle dogs [11]. The present study was set up to complement these promising findings with in vivo data in man. To the best of our knowledge, no prior papers have reported on the oral administration of ordered mesoporous silica based formulations in man.

Fenofibrate is a non-ionizable compound and exhibits low solubility over the entire physiological $\mathrm{pH}$ range [11]. It is a lipidregulating agent, indicated for the treatment of primary hyperc- 
holesterolemia, mixed dyslipidaemia or types IV and $\mathrm{V}$ hypertriglyceridemia [12]. Fenofibrate is rapidly and efficiently absorbed from the gastrointestinal tract and quantitatively converted to its pharmacologically active metabolite fenofibric acid prior to entering the systemic circulation [13]. Fenofibric acid is highly bound (>99\%) to plasma proteins and excreted primarily as glucuronide in the urine ( $70 \%$ in $24 \mathrm{~h}$ and $88 \%$ in 6 days) [13].

A variety of enabling formulations of fenofibrate are being commercialized. One such formulation is Lipanthyl ${ }^{\circledR}$, a capsule-based dosage form based on micronized fenofibrate. In the current study, the biopharmaceutical performance of fenofibrate loaded onto an OMS material was compared against the marketed formulation Lipanthyl ${ }^{\circledR}$ by measuring the systemic exposure to fenofibric acid following oral administration to fasted, healthy human volunteers.

\section{Materials and methods}

\subsection{Formulations}

Fenofibrate was loaded onto the OMS material (details on the synthesis and characteristics of this material can be found in [10]) at a $29 \%$ loading, and subsequently blended with a diluent and a disintegrant and filled into size 00 hard gelatin capsules as previously described [11]. Additional information on the characterization, in vitro performance and physical and chemical stability of the OMS-based formulation is also published elsewhere [11]. The total fenofibrate dose per capsule was $33.5 \mathrm{mg}$. The OMSbased formulation is referred to hereafter as Fenofibrate-OMS. Lipanthyl ${ }^{\circledR}$ capsules were used without modifications to the original dosage form (size 4 hard gelatin capsules containing $67 \mathrm{mg}$ of micronized fenofibrate).

\subsection{Subjects}

The clinical trial was conducted at SGS Life Science Services (Clinical Pharmacology Unit Antwerp, Belgium). Details of the subject population are provided in Table 1 .

The subjects were in a good health as assessed by detailed medical history, physical examination, 12-lead electrocardiogram (ECG), clinical laboratory tests and urinary drug screen. All subjects were non-smokers. The time span between the screening visit and the last follow-up visit was at most 6 weeks. Subjects were to discontinue all medications, except occasional paracetamol (maximum dose of $2 \mathrm{~g} /$ day and maximum of $10 \mathrm{~g} / 2$ weeks), at least 2 weeks prior to the first study drug administration. In addition, subjects were to agree not to use any medications during the

Table 1

Demographic data by treatment sequence (safety population).

\begin{tabular}{llll}
\hline Parameter & $\begin{array}{l}\text { Sequence AB } \\
\mathrm{N}=6\end{array}$ & $\begin{array}{l}\text { Sequence BA } \\
\mathrm{N}=6\end{array}$ & $\begin{array}{l}\text { All subjects } \\
\mathrm{N}=12\end{array}$ \\
\hline $\begin{array}{c}\text { Age, years } \\
\text { Median (range) }\end{array}$ & $49(40-55)$ & $43(21-49)$ & $46.5(21-55)$ \\
$\begin{array}{c}\text { Height, cm } \\
\text { Median (range) }\end{array}$ & $178(168-192)$ & $180(175-192)$ & $178(168-192)$ \\
$\begin{array}{c}\text { Weight, kg } \\
\text { Median (range) } \\
\text { BMI, kg/m } \\
\quad \text { Median (range) }\end{array}$ & $80.5(73-101)$ & $80(66-90)$ & $80(66-101)$ \\
$\begin{array}{c}\text { Sex, n (\%) } \\
\text { Male } \\
\text { Race, n (\%) } \\
\text { Caucasian }\end{array}$ & $6(100)$ & $6(100)$ & $12(100)$ \\
\hline
\end{tabular}

$\mathrm{N}=$ number of subjects; $\mathrm{n}=$ number of subjects with that observation; Treatment $\mathrm{A}$ single oral dose of $33.5 \mathrm{mg}$ Fenofibrate-OMS; Treatment B: single oral dose of $67 \mathrm{mg}$ Lipanthyl ${ }^{\circledR}$. course of the study. Subjects were not to take any alcohol and grapefruit-containing foods from $48 \mathrm{~h}$ before to $96 \mathrm{~h}$ after each study drug administration or xanthine-containing beverages and food from $12 \mathrm{~h}$ before to $96 \mathrm{~h}$ after each study drug administration. Subjects with a history of hypersensitivity to fenofibrate or a significant allergic reaction to any drug, an immunosuppressive condition, malignancy within the past 5 years, significant blood loss within 8 weeks prior to study start, diseases of the gastrointestinal tract, liver, kidneys or any other conditions known to interfere with the absorption, distribution, metabolism or elimination of drugs were excluded from the study. Individuals with active drug or alcohol abuse within 2 years prior to the initial study drug administration or consumption of large quantities of coffee or tea were also excluded.

All subjects were Caucasian males. The subjects' median (range) age was 46.5 (21-55) years. Their median (range) BMI was 25.20 $(20.8-27.8) \mathrm{kg} / \mathrm{m}^{2}$. There were no relevant differences in demographic data between the treatment sequences. Serology screening tests for hepatitis B and C and HIV, urine drug screening, and alcohol breath tests at screening were negative for all subjects. A wide range of medical history was reported across the subjects; none of these were thought to have influenced the course of the study. Concomitant diseases were reported in 1 subject $(16.7 \%)$ in each treatment sequence. Both were Gilbert's Disease. Previous medication was reported in none of the subjects and 1 subject (8.3\%) was administered Ditemer (tetanus, diphtheria vaccine) in Dosing Period 2 due to a head injury reported as an AE in Dosing Period 1.

In each of the two dosing periods, the subjects were admitted to the clinical centre on Day -1 and remained hospitalized until approximately $24 \mathrm{~h}$ after dosing (Day 2 ). Thereafter, subjects were to return to the clinical centre on Days 2 (evening), 3, 4, and 5 for post-dose bioanalysis blood sampling. A follow-up visit was planned between 5 and 7 days after the last intake of study drug. The two dosing periods were separated by a 7-day wash-out period. All study drug intakes occurred under the supervision of the investigator or his designee. The study drugs were administered between 8 and 10 a.m. In each dosing period, the subjects received an evening meal on Day -1, at least 9 h before intake of study drug, and a lunch, snack, and evening meal on Day 1. During confinement at the clinical centre, no food intake other than the standard meals was authorized. On the days of blood sampling for bioanalysis water intake was prohibited from $2 \mathrm{~h}$ pre-dose until $2 \mathrm{~h}$ postdose, with the exception of the water intake of $200 \mathrm{~mL}$ with dosing. Water was available ad libitum from $2 \mathrm{~h}$ post-dose onwards. Subjects who discontinued the study prior to completion of the scheduled study procedures for reasons such as adverse events (AE) or withdrawal of consent were invited for a follow-up visit 5-7 days after the last study drug intake. In case of an $\mathrm{AE}$, the appropriate follow-up procedure was applied.

\subsection{Safety monitoring}

In each dosing period, subjects underwent a physical examination, an assessment of vital signs and a 12-lead ECG recording on Day 1 pre-dose. Blood and urine sampling for clinical laboratory tests (haematology, serum biochemistry and urinalysis) was performed in fasting conditions. All assessments were performed within $2 \mathrm{~h}$ pre-dose. Subjects were discharged from the clinical centre upon agreement of the investigator on Day 2, after safety assessment (blood and urine samples for clinical laboratory tests, ECG, vital signs) and the last blood sampling for bioanalysis. The subjects returned to the clinical centre 5-7 days after the last dose administration for the follow-up visit for a physical examination and vital signs (HR, SBP, DBP, oral body temperature) assessment. Blood and urine samples for clinical laboratory tests were taken in fasting conditions. Any adverse or unusual event occurring from 
the study inclusion date to the last subject's visit, whether it is observed by the investigator, his staff or the subject, was recorded.

\subsection{Blood sampling}

Blood samples for the determination of fenofibric acid in plasma were taken at pre-dose and at $30 \mathrm{~min}$ and $1,2,2.5,3,3.5,4,5,6,7$, 8, 12, 16, 24 h (Day 2 morning), 36 h (Day 2 evening), 48 h (Day 3), $72 \mathrm{~h}$ (Day 4) and $96 \mathrm{~h}$ (Day 5) post-dose in each dosing period. Samples on Days 1 and 2 (morning) were taken during the subject's stay in the clinic and the subjects needed to return to the clinic for blood sampling on Days 2 (evening), 3, 4, and 5.

Each sample $(4 \mathrm{~mL}$ ) was taken by venipuncture (or indwelling cannula) in the arm and collected in vacuum tubes containing lithium heparin (Venoject, green top or equivalent). Samples were chilled immediately in an ice bath and centrifuged (at $48^{\circ} \mathrm{C}$ for $10 \mathrm{~min}$ at ca. $1500 \mathrm{~g}$ ) within $30 \mathrm{~min}$ after blood collection. The plasma obtained was transferred into two polypropylene tubes (around $500 \mu \mathrm{L}$ of plasma per tube) and stored at $-20^{\circ} \mathrm{C}$ after appropriate labelling.

One aliquot was shipped on dry ice to the analytical laboratory where the plasma was stored at $-20^{\circ} \mathrm{C}$ pending analysis. The remaining sample was shipped separately and was stored for back-up analysis.

\subsection{Analysis of plasma samples}

An analytical method for the determination of fenofibric acid in lithium heparinized human plasma was developed and validated by SGS Life Science Services, Wavre, Belgium. The frozen plasma samples were thawed at room temperature, homogenized and centrifuged. $20 \mu \mathrm{L}$ of the supernatant was mixed with $20 \mu \mathrm{L}$ of a solution of the internal standard (fenofibric acid $d_{6}$ ) and $70 \mu \mathrm{L}$ of acetonitrile and subsequently centrifuged at high speed. $20 \mu \mathrm{L}$ of the supernatant was then transferred to a 96-well plate, mixed with $80 \mu \mathrm{L}$ of a $0.05 \% \mathrm{v} / \mathrm{v}$ formic acid solution and centrifuged. $10 \mu \mathrm{L}$ of the supernatant layer was then analysed by LC/MS-MS. The LC/MS-MS system consisted of an Agilent 1100 series HPLC system (Agilent, Brussels, Belgium) equipped with a CTC HTS PAL autosampler (Cohesive Technologies, Milton Keynes, U.K.) and connected with a API 4000 mass spectrometer in the negative ion mode (AB Sciex, Nieuwerkerk a/d Ijssel, the Netherlands). The analytical column used was a Chromolith Fastgradient, RP-C18, $50 \times 2.0 \mathrm{~mm}$ I.D. (VWR, Leuven, Belgium). A gradient programme was followed with two mixtures of acetonitrile and a $0.05 \% \mathrm{v} / \mathrm{v}$ aqueous solution of formic acid: $10 / 90 \mathrm{v} / \mathrm{v}$ and 90/10 v/v.

The analytical method was validated with a lower limit of quantification (LLOQ) of $10 \mathrm{ng} / \mathrm{mL}$ and an upper limit of quantification (ULOQ) of $5000 \mathrm{ng} / \mathrm{mL}$. The response versus concentration data were fitted with a first order polynomial with $1 / C^{2}$ weighting. The withinand between-series precision, expressed as the coefficient of variation (CV) and accuracy expressed as the relative error of measurement (RE), were both below $20 \%$ at the LLOQ and below $15 \%$ at the higher concentrations which is in accordance with the preset criteria. The average carry-over was less than $20 \%$ for the analyte and less than $5 \%$ for the internal standard and the normalized matrix factor was within the acceptance criteria. The average extraction recovery was consistent over the investigated range and the 10-fold dilution of the samples did not affect precision or accuracy of the analytical results. The stability of fenofibric acid was assessed for various conditions of use and storage of the plasma samples and extracts.

\subsection{Pharmacokinetic analysis}

The pharmacokinetic analysis of the bioanalytical data was performed by SGS Life Science Services, Wavre, Belgium, using the SAS version 9.1.3. WinNonlin version 5.2. The following pharmacokinetic parameters were determined from the individual plasma concentration vs time profiles:

\begin{tabular}{|c|c|}
\hline $\mathrm{C}_{\max }$ & Maximum observed plasma concentration \\
\hline $\mathrm{C}_{\max } /$ dose & $\mathrm{C}_{\max }$ normalized to unit dose $(1 \mathrm{mg})$ \\
\hline$t_{\max }$ & Time of occurrence of $C_{\max }$ \\
\hline AUC & $\begin{array}{l}\text { Area under the plasma concentration versus } \\
\text { time curve from time zero to the last } \\
\text { sampling time at which concentrations were } \\
\text { at or above the limit of quantification [AUC } \mathrm{A}_{0-} \\
\text { t], up to } 24 \mathrm{~h} \text { post-dose }\left[\mathrm{AUC}_{0-24 \mathrm{~h}}\right] \text {, or up to } \\
48 \mathrm{~h} \text { post-dose }\left[\mathrm{AUC}_{0-48 \mathrm{~h}}\right]_{\text {calculated by the }} \\
\text { linear trapezoidal rule }\end{array}$ \\
\hline AUC $_{0-\mathrm{t}} /$ dose & $\mathrm{AUC}_{0-\mathrm{t}}$ normalized to unit dose $(1 \mathrm{mg})$ \\
\hline AUC $_{0-24 h} /$ dose & $\mathrm{AUC}_{0-24 \mathrm{~h}}$ normalized to unit dose ( $\left.1 \mathrm{mg}\right)$ \\
\hline $\mathrm{AUC}_{0-48 \mathrm{~h}} /$ dose & AUC $_{0-48 \mathrm{~h}}$ normalized to unit dose $(1 \mathrm{mg})$ \\
\hline $\mathrm{AUC}_{0-\infty}$ & $\begin{array}{l}\text { Area under the plasma concentration versus } \\
\text { time curve from time zero to infinity, } \\
\text { calculated from } \text { AUC }_{0-t}+\left(C_{t} / \lambda_{z}\right) \text {, where } C_{t} \text { is } \\
\text { the last observed quantifiable concentration }\end{array}$ \\
\hline $\mathrm{AUC}_{0-\infty} /$ dose & $\mathrm{AUC}_{0-\infty}$ normalized to unit dose $(1 \mathrm{mg})$ \\
\hline & Apparent terminal elimination rate constant \\
\hline$t_{1 / 2, \lambda z}$ & $\begin{array}{l}\text { Apparent terminal elimination half-life, } \\
\text { calculated from }(\ln 2) / \lambda_{z}\end{array}$ \\
\hline
\end{tabular}

Calculation of pharmacokinetic parameters was performed using the actual sample collection times. If the actual sampling time of an individual sample was greater than $20 \%$ different from the scheduled sampling time, the individual concentration was excluded from the descriptive statistics for the concentration-time table and mean concentration-time graphs. If the percentage of the AUC extrapolated exceeded $20 \%$ of the total $\mathrm{AUC}_{0-\infty}$, the $\mathrm{AUC}_{0-\infty}$ was excluded from any statistical evaluation. $\lambda_{z}$ was to be calculated using at least 3 data-points not including the peak plasma concentration $\left(C_{\max }\right)$. The acceptable adjusted $R^{2}$ value was $\geqslant 0.85$. If this condition was not fulfilled, then the related parameters were not tabulated.

\subsection{Statistical methods}

Descriptive statistics applied in this study included the number of data (N), arithmetic mean, standard deviation (SD), coefficient of variation $(\mathrm{CV})$, standard error (SE), \% confidence interval $(\mathrm{CI})$ of the mean, median, minimum and maximum. For continuous parameters, descriptive statistics were presented when the number of nonmissing data points was greater or equal to 2 . All statistical inferential tests were interpreted at the 5\% two-sided significance level.

Strict statistical criteria were not used to determine the sample size for this study. The number of subjects included in this study should give reasonable precision around the estimates derived for the pharmacokinetic analysis. Allocation of each subject to one of the 2 treatment sequences ( $A B$ and $B A$ ) was described in a randomization list prepared by the Biostatistics Department of SGS Life Science Services using SAS software (SAS Inc., Cary, NC, USA).

The two-period, two-sequence cross-over design with phases of treatment separated by an adequate wash-out period was chosen in such a manner that any formulation effect could be distinguished from other effects. The cross-over design provided a within-subject comparison for the treatments.

Comparison between treatments was assessed on lntransformed parameters $\left(\mathrm{C}_{\max } /\right.$ dose, $\mathrm{AUC}_{0 \mathrm{t}} /$ dose, $\mathrm{AUC}_{0-24 \mathrm{~h}} /$ dose, 
$\mathrm{AUC}_{0-48 \mathrm{~h}} /$ dose, $\mathrm{AUC}_{0-\infty} /$ dose, $\left.\mathrm{t}_{1 / 2, \lambda z}\right)$ by means of a mixed effect analysis of variance (ANOVA) with treatment, sequence, and period as fixed effects, and subject (nested within sequence) as random effect. Point estimates were calculated as the geometric mean of the individual ratios of each parameter for the test treatment (33.5 mg Fenofibrate-OMS) relative to the reference treatment $\left(67 \mathrm{mg}\right.$ Lipanthyl ${ }^{\circledR}$ ) and expressed as a percentage. The $90 \%$ CIs of the point estimates (PE) were calculated using the mean square error of the ANOVA. As $t_{\max }$ is a discrete variable dependent on selected blood sampling times, the same comparison $(33.5 \mathrm{mg}$ Fenofibrate-OMS versus $67 \mathrm{mg}$ Lipanthyl ${ }^{\circledR}$ ) was assessed using a nonparametric test (Koch procedure). The 90\% CI was calculated by the Hodges-Lehmann method.

\subsection{Regulatory compliance}

This study was conducted in accordance with the ethical principles that have their origin in the Declaration of Helsinki and the International Conference on Harmonization (ICH) Note for Guidance on Good Clinical Practice (GCP) (CPMP/ICH/135/95) and with applicable local requirements. Prior to the performance of any study-specific procedure, written informed consent was obtained from each subject. The final clinical trial protocol (CTP) as well as the informed consent and other information that required preapproval were reviewed and approved by an Independent Ethics Committee (IEC; Commissie voor Medische Ethiek - Ziekenhuisnetwerk Antwerpen - ZNA/OCMW, Antwerp, Belgium) according to specifications outlined in the applicable regulations.

\section{Results}

\subsection{Analytics}

In the second administration period of the study, a quantifiable pre-dose plasma concentration was found in 4 subjects. In each case, the pre-dose plasma concentration was lower than $5 \%$ of the corresponding $\mathrm{C}_{\max }$. In accordance with the regulatory guidelines, these data were used as such in the pharmacokinetic analysis. Since the lower limit of quantification (LLOQ) for plasma pharmacokinetic analysis was set at $10.0 \mathrm{ng} / \mathrm{mL}$, all analytical values below this value were entered in the database ' $<10 \mathrm{ng} / \mathrm{mL}$ '. For each plasma sample, the difference between the actual sampling time and the scheduled sampling time was lower than $20 \%$.

\subsection{Fenofibric acid pharmacokinetics}

The plasma concentration vs time profiles of fenofibric acid after administration of Fenofibrate-OMS and Lipanthyl ${ }^{\circledR}$ are presented in Fig. 1.

An overview of all pharmacokinetic parameters is provided in Table 2 and a statistical comparison of the pharmacokinetic parameters is presented in Table 3.

Statistical comparison of the dose-normalized measures of extent of exposure (Table 3) reveals significantly higher values for Fenofibrate-OMS, with point estimates of $129.9 \%, 154.1 \%$, $140.5 \%$ and $126.7 \%$ for $\mathrm{AUC}_{0-\mathrm{t}} /$ dose, $\mathrm{AUC}_{0-24 \mathrm{~h}} /$ dose, $\mathrm{AUC}_{0-48 \mathrm{~h}} /$ dose and $\mathrm{AUC}_{0-\infty} /$ dose, respectively. The data in Table 3 also show a significant increase in $\mathrm{C}_{\max }$ /dose (point estimate of $177 \%$ ), a reduction in $\mathrm{t}_{\max }(-0.75 \mathrm{~h})$ and a modest yet significant decrease in apparent terminal half-life $\left(t_{1 / 2, \lambda z}\right)$ following administration of FenofibrateOMS.
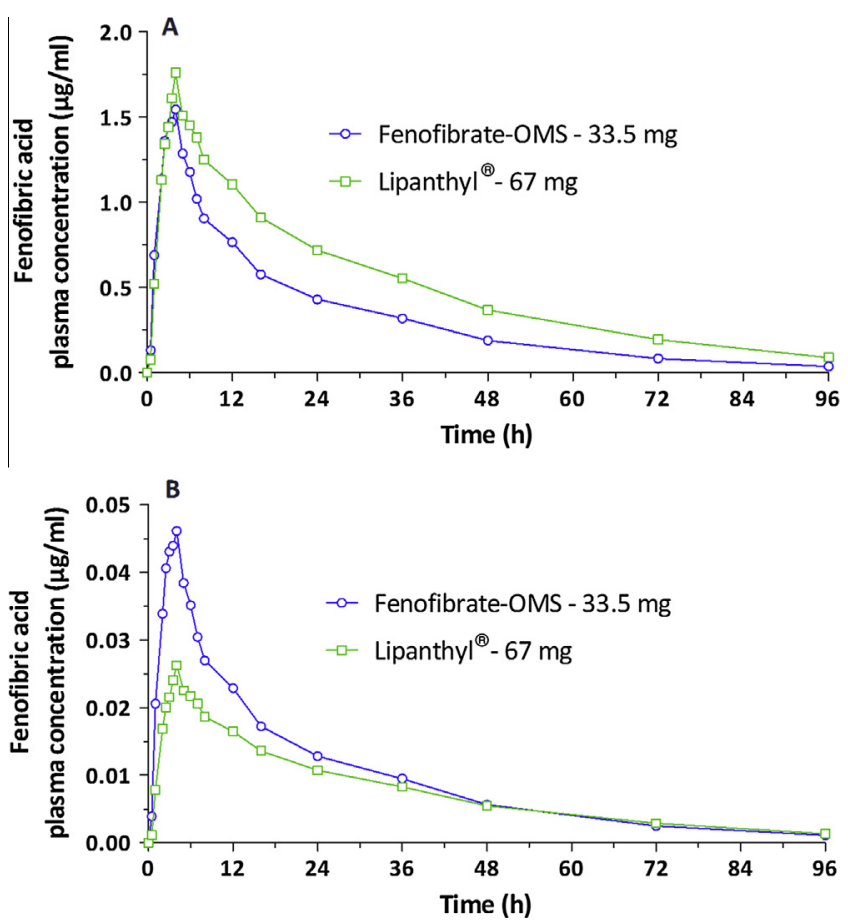

Fig. 1. (A) Mean $(n=12)$ plasma concentration vs time profiles after single administration of one capsule containing $33.5 \mathrm{mg}$ of fenofibrate formulated with OMS (Fenofibrate-OMS) or one capsule containing $67 \mathrm{mg}$ of micronized fenofibrate (Lipanthyl $\left.{ }^{\circledR}\right)$; (B) the same data after normalization to $1 \mathrm{mg}$ dose.

Table 2

Fenofibric acid pharmacokinetic parameters. All data (except $t_{\max }$ data) are presented as mean \pm standard deviation calculated from the 12 subjects having completed the two treatment periods. For $t_{\max }$, median values are provided with the range presented in brackets.

\begin{tabular}{lll}
\hline Pharmacokinetic parameter & Fenofibrate-OMS & Lipanthyl $^{\circledR}$ \\
\hline $\mathrm{C}_{\max }(\mu \mathrm{g} / \mathrm{mL})$ & $1.67 \pm 0.29$ & $1.96 \pm 0.65$ \\
$\mathrm{t}_{\max }(\mathrm{h})$ & $3.50(2.00-5.00)$ & $4.00(2.00-6.00)$ \\
$\mathrm{AUC}_{0-\mathrm{t}}(\mu \mathrm{g} \mathrm{h} / \mathrm{mL})$ & $30.8 \pm 13.4$ & $47.9 \pm 22.0$ \\
$\mathrm{AUC}_{0-24 \mathrm{~h}}(\mu \mathrm{g} \mathrm{h} / \mathrm{mL})$ & $18.7 \pm 4.7$ & $24.9 \pm 8.6$ \\
$\mathrm{AUC}_{0-48 \mathrm{~h}}(\mu \mathrm{g} \mathrm{h} / \mathrm{mL})$ & $26.3 \pm 9.1$ & $37.8 \pm 14.7$ \\
$\mathrm{AUC}_{0-\infty}(\mu \mathrm{g} \mathrm{h} / \mathrm{mL})$ & $32.3 \pm 14.7$ & $51.9 \pm 26.0$ \\
$\mathrm{t}_{1 / 2, \lambda z}(\mathrm{~h})$ & $17.0 \pm 6.2$ & $22.1 \pm 8.8$ \\
$\mathrm{C}_{\max } /$ dose $(\mu \mathrm{gg} / \mathrm{mL} / \mathrm{mg})$ & $0.0498 \pm 0.0087$ & $0.0293 \pm 0.0097$ \\
$\mathrm{AUC}_{0-\mathrm{t}} /$ dose $(\mu \mathrm{g} \mathrm{h} / \mathrm{mL} / \mathrm{mg})$ & $0.921 \pm 0.401$ & $0.715 \pm 0.329$ \\
$\mathrm{AUC}_{0-24 \mathrm{~h}} /$ dose $(\mu \mathrm{g} \mathrm{h} / \mathrm{mL} / \mathrm{mg})$ & $0.559 \pm 0.140$ & $0.372 \pm 0.128$ \\
$\mathrm{AUC}_{0-48 \mathrm{~h}} /$ dose $(\mu \mathrm{g} \mathrm{h} / \mathrm{mL} / \mathrm{mg})$ & $0.784 \pm 0.272$ & $0.565 \pm 0.220$ \\
\hline
\end{tabular}

Fenofibrate-OMS treatment: single oral dose of $33.5 \mathrm{mg}$ fenofibrate formulated with ordered mesoporous silica; Lipanthyl ${ }^{\circledR}$ treatment: single oral dose of $67 \mathrm{mg}$ micronized fenofibrate.

$\mathrm{C}_{\max }=$ maximum observed plasma concentration.

$\mathrm{C}_{\max } /$ dose $=\mathrm{C}_{\max }$ normalized to unit dose $(1 \mathrm{mg})$.

$\mathrm{t}_{\max }=$ time of occurrence of $\mathrm{C}_{\max }$.

AUC $=$ area under the plasma concentration versus time curve from time zero to the last sampling time at which concentrations were at or above the limit of quantification $\left[A U C_{0-\mathrm{t}}\right.$ ], up to $24 \mathrm{~h}$ post-dose $\left[\mathrm{AUC}_{0-24 \mathrm{~h}}\right.$ ], or up to $48 \mathrm{~h}$ post-dose [ $\mathrm{AUC}_{0-48 \mathrm{~h}}$ ] calculated by the linear trapezoidal rule.

$\mathrm{AUC}_{0-\mathrm{t}} /$ dose $=\mathrm{AUC}_{0-\mathrm{t}}$ normalized to unit dose $(1 \mathrm{mg}) ; \mathrm{AUC}_{0-24 \mathrm{~h}} /$ dose $=\mathrm{AUC}_{0-24 \mathrm{~h}}$ normalized to unit dose $(1 \mathrm{mg})$; $\mathrm{AUC}_{0-48 \mathrm{~h}} /$ dose $=\mathrm{AUC}_{0-48 \mathrm{~h}}$ normalized to unit dose $(1 \mathrm{mg}) ; \mathrm{AUC}_{0-\infty}=$ Area under the plasma concentration versus time curve from time zero to infinity, calculated from $\mathrm{AUC}_{0-\mathrm{t}}+\left(\mathrm{C}_{t} / \lambda_{z}\right)$, where $C_{t}$ is the last observed quantifiable concentration; $\mathrm{AUC}_{0-\infty} /$ dose $=\mathrm{AUC}_{0-\infty}$ normalized to unit dose $(1 \mathrm{mg})$. $\lambda_{z}=$ apparent terminal elimination rate constant; $t_{1 / 2, \lambda z}=$ apparent terminal elimination half-life, calculated from $(\ln 2) / \lambda_{\mathrm{z}}$.

\subsection{Safety}

No serious adverse events occurred during this study and none of the subjects prematurely discontinued the study due to an 
Table 3

Statistical comparison of fenofibric acid pharmacokinetic parameters between Fenofibrate-OMS and Lipanthyl ${ }^{\circledR}$.

\begin{tabular}{lll}
\hline Pharmacokinetic parameter & \multicolumn{2}{l}{ Fenofibrate-OMS vs Lipanthyl ${ }^{\circledR}$} \\
\cline { 2 - 3 } & Point estimate $(90 \% \mathrm{CI})^{\mathrm{a}}$ & p-value $^{\mathrm{b}}$ \\
\hline $\mathrm{C}_{\max } /$ dose & $177.1(152.5-205.8)$ & $<0.0001$ \\
$\mathrm{t}_{\max }$ & $-0.75(-1.25$ to -0.25$)$ & 0.0344 \\
$\mathrm{AUC}_{0-\mathrm{t}} /$ dose & $129.9(120.5-140.0)$ & $<0.0001$ \\
$\mathrm{AUC}_{0-24 \mathrm{~h}} /$ dose & $154.1(136.8-173.5)$ & $<0.0001$ \\
$\mathrm{AUC}_{0-48 \mathrm{~h}} /$ dose & $140.5(128.3-153.8)$ & $<0.0001$ \\
$\mathrm{AUC}_{0-\infty} /$ dose & $127.0(118.0-136.6)$ & 0.0002 \\
$\mathrm{t}_{1 / 2, \lambda \mathrm{z}}$ & $77.6(70.0-86.0)$ & 0.0012 \\
\hline
\end{tabular}

Fenofibrate-OMS treatment: single oral dose of $33.5 \mathrm{mg}$ fenofibrate formulated with ordered mesoporous silica; Lipanthyl ${ }^{\circledR}$ treatment: single oral dose of $67 \mathrm{mg}$ micronized fenofibrate.

a Point estimate and $90 \% \mathrm{CI}$ of the least-squares geometric percentage ratio (ANOVA). For $t_{\max }$, comparison was assessed between Fenofibrate-OMS and Lipanthyl ${ }^{\circledR}$ using the Koch procedure; the Hodges-Lehmann non-parametric estimate of location shift between Fenofibrate-OMS and Lipanthyl ${ }^{\circledR}$ based on untransformed data is provided with its $90 \%$ two sided $\mathrm{CI}$.

b Probability of no difference between treatments (ANOVA; non-parametric test for $\left.t_{\max }\right)$.

adverse event. In total, 6 treatment-emergent adverse events were reported in 3 subjects (25.0\%): 2 subjects (16.7\%) in the period following administration of Fenofibrate-OMS and in 1 (8.3\%) in the period following administration of Lipanthyl ${ }^{\circledR}$. All treatmentemergent adverse events were mild in severity and were seen in at most one subject (nausea and back pain in one subject each and contusion, head injury, nail injury, and spinal cord injury cervical in one subject). One event was considered by the investigator to have a reasonable possibility of causal relationship with the study drug (nausea in the period following administration of Fenofibrate-OMS). No relevant differences in clinical laboratory test data were observed between Fenofibrate-OMS and Lipanthyl ${ }^{\circledR}$ and no clinically relevant changes from baseline in median values of any ECG parameter or vital signs were observed following administration of the study drug. No abnormalities were noted in any of the subjects during physical examination.

\section{Discussion}

In this study, the pharmaceutical performance of fenofibrate formulated with an ordered mesoporous silica material (Fenofibrate-OMS) was compared against the marketed product Lipanthyl ${ }^{\circledR}$. Twelve healthy volunteers received a $33.5 \mathrm{mg}$ dose of Fenofibrate-OMS and $67 \mathrm{mg}$ of Lipanthyl ${ }^{\circledR}$ in two sequential dosing periods. Plasma concentrations of fenofibric acid, the pharmacologically active metabolite of fenofibrate, were monitored up to $96 \mathrm{~h}$ post-dose. All subjects received the study drug as planned and all subjects completed the study as planned. Statistical analyses on the measures of the rate and extent of absorption were performed on the dose-normalized data. This dose-normalization is justifiable based on the results of prior study that demonstrated dose proportionality between a $16.5 \mathrm{mg}$ and a $33 \mathrm{mg}$ fenofibrate dose following oral administration of Fenofibrate-OMS to fasted beagle dogs [11].

Overall, the pharmacokinetic data revealed a significant increase in the extent of absorption following administration of Fenofibrate-OMS. The extent of absorption expressed as the dose-normalized AUC from time zero to the $24 \mathrm{~h}\left(\mathrm{AUC}_{0-24 \mathrm{~h}} /\right.$ dose) of $48 \mathrm{~h}\left(\mathrm{AUC}_{0-48 \mathrm{~h}} /\right.$ dose $)$ was significantly higher for FenofibrateOMS, with point estimates of ca $154 \%$ and $140 \%$, respectively (Table 3), indicating an increase in systemic exposure of around $54 \%$ and $40 \%$, respectively. These differences are significant within the $90 \% \mathrm{CI}$, which is above the minimum acceptance interval currently required by the European Medicines Agency (EMA) to conclude to bioequivalence (80-125\%). Fenofibric acid exposure assessed until the last measurable concentration $\left(\mathrm{AUC}_{0 \mathrm{t}} / \mathrm{dose}\right)$ or extrapolated to infinity $\left(\mathrm{AUC}_{0-\infty} /\right.$ dose) was statistically significantly increased but to a lesser extent (30\% and $27 \%$, respectively) and with $90 \%$ CIs overlapping with the upper limit of the acceptance interval (80-125\%) required to conclude to bioequivalence.

The data also indicated an increased rate of absorption for Fenofibrate-OMS: the dose-normalized maximum fenofibric acid plasma concentration $\left(\mathrm{C}_{\max } /\right.$ dose $)$ was increased by $77 \%$ $(p<0.0001)$ and the time to reach the maximum plasma concentration $\left(t_{\max }\right)$ was reduced by $0.75 \mathrm{~h}(\mathrm{p}<0.05)$. The increased rate and extent of absorption following administration of FenofibrateOMS can be related to the release rate of fenofibrate from OMS which is faster than the dissolution rate of micronized fenofibrate (Lipanthyl ${ }^{\circledR}$ ) [11], thus providing a higher driving force for drug absorption during gastrointestinal transit. These results, indicative of a higher pharmaceutical performance of Fenofibrate-OMS, are in line with those obtained previously in beagle dogs [11].

Single doses of Fenofibrate-OMS were safe and well tolerated. No relevant differences in safety and tolerability profile were observed when comparing a single dose of Fenofibrate-OMS and Lipanthyl ${ }^{\circledR}$.

\section{Conclusion}

The results of this study indicated that administration of an ordered mesoporous silica based formulation of fenofibrate resulted in an increased rate and extent of absorption when compared to a marketed product. In addition, single doses of the ordered mesoporous silica based formulation were well tolerated by all volunteers. The present study is the first to demonstrate the bioavailability-enhancing potential of this novel formulation approach in man, and evidences the utility of this technique to overcome bioavailability problems associated with poor solubility.

\section{Acknowledgements}

This study was financially supported by the Flemish Institute for the Promotion of Innovation through Science and Technology (IWT-Vlaanderen). JAM acknowledges the Flemish Government for long term structural funding (Methusalem). Controlled release is a research topic of interuniversity attraction poles (IAP-PAI).

\section{References}

[1] M. Alcoutlabi, G.B. McKenna, Effects of confinement on material behaviour at the nanometer size scale, J. Phys. Condens. Matter 17 (2005) 461-524.

[2] M. Van Speybroeck, V. Barillaro, T.D. Thi, R. Mellaerts, J. Martens, J. Van Humbeeck, J. Vermant, P. Annaert, G. Van den Mooter, P. Augustijns, Ordered mesoporous silica material SBA-15: a broad-spectrum formulation platform for poorly soluble drugs, J. Pharm. Sci. 98 (2009) 2648-2658.

[3] F. Kiekens, S. Eelen, L. Verheyden, T. Daems, J. Martens, G.V. Den Mooter, Use of ordered mesoporous silica to enhance the oral bioavailability of ezetimibe in dogs, J. Pharm. Sci. 101 (2012) 1136-1144.

[4] T. Azaïs, C. Tourné-Péteilh, F. Aussenac, N. Baccile, C. Coelho, J.-M. Devoiselle, F. Babonneau, Solid-state NMR study of ibuprofen confined in MCM-41 material, Chem. Mater. 18 (2006) 6382-6390.

[5] R. Mellaerts, R. Mols, P. Kayaert, P. Annaert, J. Van Humbeeck, G. Van den Mooter, J.A. Martens, P. Augustijns, Ordered mesoporous silica induces pHindependent supersaturation of the basic low solubility compound itraconazole resulting in enhanced transepithelial transport, Int. J. Pharm. 357 (2008) 169-179.

[6] M. Van Speybroeck, R. Mellaerts, T.D. Thi, J.A. Martens, J. Van Humbeeck, P. Annaert, G. Van den Mooter, P. Augustijns, Preventing release in the acidic environment of the stomach via occlusion in ordered mesoporous silica enhances the absorption of poorly soluble weakly acidic drugs, J. Pharm. Sci. 100 (2011) 4864-4876.

[7] M. Van Speybroeck, R. Mellaerts, R. Mols, T.D. Thi, J.A. Martens, J. Van Humbeeck, P. Annaert, G. Van den Mooter, P. Augustijns, Enhanced absorption of the poorly soluble drug fenofibrate by tuning its release rate from ordered mesoporous silica, Eur. J. Pharm. Sci. 41 (2010) 623-630.

[8] R. Mellaerts, R. Mols, J.A.G. Jammaer, C.A. Aerts, P. Annaert, J. Van Humbeeck, G. Van den Mooter, P. Augustijns, J.A. Martens, Increasing the oral bioavailability 
of the poorly water soluble drug itraconazole with ordered mesoporous silica, Eur. J. Pharm. Biopharm. 69 (2008) 223-230.

[9] M. Van Speybroeck, R. Mols, R. Mellaerts, T.D. Thi, J.A. Martens, J.V. Humbeeck P. Annaert, G.V. den Mooter, P. Augustijns, Combined use of ordered mesoporous silica and precipitation inhibitors for improved oral absorption of the poorly soluble weak base itraconazole, Eur. J. Pharm. Biopharm. 75 (2010) 354-365.

[10] J. Jammaer, A. Aerts, J. D’Haen, J.W. Seo, J.A. Martens, Convenient synthesis of ordered mesoporous silica at room temperature and quasi-neutral pH, J. Mater. Chem. 19 (2009) 8290-8293.
[11] K. Bukara, L. Shueller, J. Rosier, T. Daems, L. Verheyden, S. Eelen, J.A. Martens, G. V. Mooter, B. Bugarski, F. Kiekens, In vivo performance of fenofibrate formulated with ordered mesoporous silica versus 2-marketed formulations: a comparative bioavailability study in beagle dogs, J. Pharm. Sci., 2016 (in press), http://dx.doi.org/10.1016/j.xphs.2016.05.019.

[12] R.S. Rosenson, Fenofibrate: treatment of hyperlipidemia and beyond, Expert Rev. Cardiovasc. Ther. 6 (2008) 1319-1330.

[13] J.A. Balfour, D. McTavish, R.C. Heel, Fenofibrate. A review of its pharmacodynamic and pharmacokinetic properties and therapeutic use in dyslipidemia, Drugs 40 (1990) 260-290. 